\title{
Risk of cancer following primary total hip replacement or primary resurfacing arthroplasty of the hip: a retrospective cohort study in Scotland
}

\author{
D H Brewster ${ }^{\star}, 1$, D L Stockton ${ }^{1}$, A Reekie ${ }^{1}$, G P Ashcroft ${ }^{2}$, C R Howie ${ }^{3}$, D E Porter ${ }^{3}$ and R J Black ${ }^{1}$ \\ ${ }^{1}$ Information Services Division, NHS National Services Scotland, Gyle Square, 1 South Gyle Crescent, Edinburgh EH12 9EB, \\ UK; ${ }^{2}$ Department of Orthopaedics, School of Medicine and Dentistry, University of Aberdeen, Foresterhill, Aberdeen \\ AB25 2ZD, UK and ${ }^{3}$ Department of Orthopaedics, The Royal Infirmary of Edinburgh, Old Dalkeith Road, Edinburgh EH16 4SU, UK
}

Background: Release and dispersion of particles arising from corrosion and wear of total hip arthroplasty (THA) components has raised concerns about a possible increased risk of cancer. Concerns have been heightened by a recent revival in the use of metalon-metal (MoM) hip prostheses.

Methods: From a linked database of hospital discharge, cancer registration, and mortality records, we selected a cohort of patients who underwent primary THA (1990-2009) or primary resurfacing arthroplasty (mainly 2000-2009) in Scotland, with followup to the end of 2010. Available operation codes did not enable us to distinguish MoM THAs. Indirectly standardised incidence ratios (SIRs) were calculated for selected cancers with standardisation for age, sex, deprivation, and calendar period.

Results: The study cohort included 71990 patients yielding 547001 person-years at risk (PYAR) and 13946 cancers diagnosed during follow-up. For the total period of observation combined, the risks of all cancers (SIR: 1.05; 95\% Cl: confidence interval 1.041.07), prostate cancer (SIR: 1.07; 95\% Cl: 1.01-1.14), and multiple myeloma (SIR: 1.22; 95\% Cl: 1.06-1.41) were increased. These modest increases in risk emerged in the context of effectively multiple tests of statistical significance, and may reflect inadequate adjustment for confounding factors. For 1317 patients undergoing primary resurfacing arthroplasty between 2000 and 2009 (PYAR $=5698)$, the SIR for all cancers $(n=39)$ was 1.23 (95\% Cl: 0.87-1.68).

Conclusion: In the context of previous research, these results do not suggest a major cause for concern. However, the duration of follow-up of patients receiving recently introduced, new-generation MoM prostheses is too short to rule out a genuinely increased risk of cancer entirely.

Since the earliest recorded attempts at hip replacement surgery more than 100 years ago (Knight et al, 2011), millions of patients have undergone total hip arthroplasty (THA) worldwide (Polyzois et al, 2012). A variety of materials have been used for the bearing surfaces of hip prostheses, the principal modern options being metal-on-polyethylene, metal-on-metal, ceramic-on-polyethylene, and ceramic-on-ceramic. Systemic exposure to chromium, cobalt, nickel, and aluminium alloys can occur because of the formation of metal wear nanoparticles that are released both from metal-onmetal and metal-on-polyethylene bearings, resulting in a postoperative increase in metal ion levels at different organ sites, especially those comprising the lymphoreticular system. These particles circulate locally and systemically, penetrate cell plasma membranes, bind to cellular proteins and enzymes, cause chromosome aberrations and DNA damage, modulate cytokine expression, and might, therefore, cause long-term increased risks of 
cancer (Visuri et al, 2010; Mäkelä et al, 2012; Polyzois et al, 2012). Although a Working Group established by the International Agency for Research on Cancer concluded that there is inadequate evidence in humans for the carcinogenicity of metallic implants, metallic foreign bodies, and orthopaedic implants of complex composition (IARC Monographs on the Evaluation of Carcinogenic Risks to Humans, 1999), this finding does not rule out a risk of cancer entirely, and the evidence reviewed pre-dated the emergence of the modern generation of metal-on-metal hip prostheses (Cohen, 2011).

Two early cohort studies of cancer risk following THA found an increased risk of lymphohaematopoietic malignancies (Gillespie et al, 1988; Visuri and Koskenvuo, 1991), but apart from an excess of multiple myeloma emerging during long-term follow-up (Signorello et al, 2001), other studies (Mathiesen et al, 1995; Nyrén et al, 1995; Gillespie et al, 1996; Visuri et al, 1996, 2010; Olsen et al, 1999; Paavolainen et al, 1999; Goldacre et al, 2005; Mäkelä et al, 2012) have not shown an excess risk of these cancers. However, some other studies have reported excess risks of melanoma of the skin (Nyrén et al, 1995; Olsen et al, 1999; Signorello et al, 2001; Mäkelä et al, 2012), prostate cancer (Nyrén et al, 1995; Signorello et al, 2001), kidney cancer (Nyrén et al, 1995), and basal cell carcinoma of the skin, specifically in patients with modern generation metal-on-metal hip replacements (Mäkelä et al, 2012). Although there have been case reports of bone and soft tissue sarcomas arising adjacent to orthopaedic implants (IARC Monographs on the Evaluation of Carcinogenic Risks to Humans, 1999; Vahey et al, 1995), none of the cohort studies so far conducted have demonstrated a statistically significant excess risk of these kinds of cancers. Recent metaanalyses and reviews of studies of cancer risk following THA (as well as, in some cases, total knee arthroplasty) have also identified increased risks of skin melanoma (Visuri et al, 2003, 2006; Onega et al, 2006), prostate cancer (Visuri et al, 2003, 2006; Onega et al, 2006), cancer of the endometrium (Visuri et al, 2003), and cancers of the urinary tract and mouth/pharynx (Onega et al, 2006). More recently, a record linkage study between the National Joint Registry of England and hospital episode statistics did not find any evidence of an association between metal-onmetal hip replacements and increased risk of admission to hospital with cancer in the first 7 years after hip replacement (Smith et al, 2012).

Recent concerns and publicity about a possible association between the new generation of metal-on-metal hip joint replacement devices and subsequent risk of cancer prompted us to investigate the risk of cancer among patients treated with THA or primary resurfacing arthroplasty of the hip in Scotland (estimated total mid-year population approximately 5.25 million in 2011).

\section{MATERIALS AND METHODS}

Study population. The study population was drawn from the permanently linked database of acute hospital discharges, cancer registrations, and mortality records in Scotland (Kendrick and Clarke, 1993). From National Health Service (NHS) acute hospital discharge records, we selected patients undergoing primary total hip replacement or primary resurfacing arthroplasty of the hip during the period 1990-2009 inclusive, based on the following OPCS-4 procedure codes (Office of Population Censuses and Surveys, 1990):

- W37.1: Primary total prosthetic replacement of hip joint using cement.

- W38.1: Primary total prosthetic replacement of hip joint not using cement.
- W39.1: Primary total prosthetic replacement of hip joint NEC.

- W58.1 + Z84.3: Primary resurfacing arthroplasty of joint + hip joint.

These OPCS-4 codes include, but are not specific to, metal-onmetal hip replacements, which, in common with the rest of the world, increased in use in Scotland between 2005 and 2009. For example, it is not possible to distinguish large diameter head metalon-metal total hip replacements.

Each member of the study cohort was followed up for cancer incidence from the date of their earliest relevant hip surgery until death or the end of 2010 (whichever occurred first). As in other recent studies (Visuri et al, 2010; Mäkelä et al, 2012), follow-up was not censored at the date of diagnosis of first cancer; all primary cancers diagnosed during the follow-up period were counted as observed cases. Cancers occurring before each patient's hip operation were disregarded.

Statistical methods. Indirectly standardised incidence ratios (SIRs) were calculated for selected cancers based on the ratio of observed to expected numbers of cancers. The list of cancers investigated (Appendix 1) was determined before analysis, and was based on excess risks of specific cancers reported from previous studies, as well as a list of cancers identified in an unpublished study from Wales, which had been a source of concern. Expected numbers of cancers were calculated by applying national age-, sex-, deprivation category-, and calendar period-specific (and cancerspecific) rates to the age-, sex-, deprivation category-, and calendar period-specific person-years at risk (PYAR) in the study cohort. Rates were calculated using population denominator data sourced from the General Register Office for Scotland (now part of National Records of Scotland). The Scottish Index of Multiple Deprivation (SIMD) 2004 (Scottish Government, 2004) was used as a postcode-referenced, small area indicator of socioeconomic position. This has seven domains (income, employment, education, housing, health, crime, and geographical access) at 'datazone' level (areas with approximately 500-1000 household residents), which have been combined into an overall index to identify area concentrations of multiple deprivation. SIMD population estimates are only available from 1996 onwards, so we used 1996 estimates for the period 1990-1995. We calculated 95\% confidence intervals (CIs) for SIRs by assuming that the observed numbers of cancers follow a Poisson distribution. SIRs with 95\% CIs that did not include the value 1.00 were regarded as statistically significant. SIRs were calculated for the total period of observation, and also partitioned by a period of hip surgery (1990-1994, 1995-1999, 2000-2004, and 2005-2009), and by time since hip operation $(<1$ year, 1-4 years, $5-9$ years, and $\geqslant 10$ years). In addition, we performed a subgroup analysis of patients recorded as undergoing primary resurfacing arthroplasty during 2000-2009.

\section{RESULTS}

The distribution and characteristics of the study population are summarised in Table 1. Overall, the study cohort included 71990 patients yielding 547001 PYAR. The female-to-male ratio was 1.6:1.0, and almost $80 \%$ of patients were aged 60 years or older at the time of their first relevant hip surgery. Higher proportions of patients were from the second and third least deprived fifths of SIMD 2004, whereas lower proportions were from the least and (especially) the most deprived fifth. The overwhelming majority of patients ( $>98 \%$ in both sexes combined) were recorded as having primary total hip replacement rather than primary resurfacing arthroplasty as their first relevant procedure. More than $99 \%$ (1317 out of 1325) of primary resurfacing arthroplasties were performed during 2000-2009. In both sexes combined, the mean 
Table 1. Distribution and summary characteristics of the study population

\begin{tabular}{|c|c|c|c|c|c|c|}
\hline & \multicolumn{2}{|c|}{ Males } & \multicolumn{2}{|c|}{ Females } & \multicolumn{2}{|c|}{ Persons } \\
\hline & Number & $\%$ & Number & $\%$ & Number & $\%$ \\
\hline \multicolumn{7}{|l|}{ Age group (years) } \\
\hline $\begin{array}{l}<40 \\
40-49 \\
50-59 \\
60-69 \\
70-79 \\
\geqslant 80\end{array}$ & \begin{tabular}{c|}
637 \\
1469 \\
4960 \\
9575 \\
8656 \\
2501
\end{tabular} & $\begin{array}{c}2.3 \\
5.3 \\
17.8 \\
34.4 \\
31.1 \\
9.0\end{array}$ & $\begin{array}{c}730 \\
1651 \\
5955 \\
13434 \\
15723 \\
6699\end{array}$ & $\begin{array}{c}1.7 \\
3.7 \\
13.5 \\
30.4 \\
35.6 \\
15.2\end{array}$ & $\begin{array}{c}1367 \\
3120 \\
10915 \\
23009 \\
24379 \\
9200\end{array}$ & \begin{tabular}{c|}
1.9 \\
4.3 \\
15.2 \\
32.0 \\
33.9 \\
12.8
\end{tabular} \\
\hline \multicolumn{7}{|l|}{ Deprivation fifth } \\
\hline $\begin{array}{l}1 \text { - Least deprived } \\
2 \\
3 \\
4 \\
5 \text { - Most deprived }\end{array}$ & $\begin{array}{l}5277 \\
6474 \\
6566 \\
5413 \\
4068\end{array}$ & $\begin{array}{l}19.0 \\
23.3 \\
23.6 \\
19.5 \\
14.6\end{array}$ & $\begin{array}{c}8137 \\
9496 \\
10118 \\
9178 \\
7263\end{array}$ & $\begin{array}{l}18.4 \\
21.5 \\
22.9 \\
20.8 \\
16.4\end{array}$ & $\begin{array}{l}13414 \\
15970 \\
16684 \\
14591 \\
11331\end{array}$ & $\begin{array}{l}18.6 \\
22.2 \\
23.2 \\
20.3 \\
15.7\end{array}$ \\
\hline \multicolumn{7}{|l|}{ Type of surgery } \\
\hline $\begin{array}{l}\text { Primary total hip replacement } \\
\text { Primary resurfacing arthroplasty }\end{array}$ & $\begin{array}{c}26909 \\
889\end{array}$ & $\begin{array}{c}96.8 \\
3.2\end{array}$ & $\begin{array}{c}43756 \\
436\end{array}$ & $\begin{array}{c}99.0 \\
1.0\end{array}$ & $\begin{array}{c}70665 \\
1325\end{array}$ & $\begin{array}{c}98.2 \\
1.8\end{array}$ \\
\hline Total & 27798 & 100 & 44192 & 100 & 71990 & 100 \\
\hline $\begin{array}{l}\text { Mean age at study entry (years) } \\
\text { Median calendar year at study entry } \\
\text { Mean number of years of follow-up } \\
\text { Person-years at risk } \\
\text { Number of cancers diagnosed during } \\
\text { follow-up }\end{array}$ & & & & & & \\
\hline
\end{tabular}

age at study entry was 68 years and the mean number of years of follow-up was 7.6. During follow-up, 13946 cancers were diagnosed in the whole study cohort and the mean age at diagnosis of cancer was 76.1 years.

Table 2 shows the observed numbers of cancers, SIRs, and 95\% CIs, by calendar period of hip operation. Standardised incidence ratios were significantly higher than expected for cutaneous melanoma and for basal cell carcinoma of the skin among patients operated on during 2005-2009 (SIR: 1.42; 95\% CI: 1.07-1.86 and SIR: 1.12 ; $95 \% 1.01-1.24$, respectively); for prostate cancer among patients operated on during 1990-2009 (SIR: 1.07; 95\% CI: 1.011.14); for multiple myeloma and other immunoproliferative neoplasms among patients operated on during 1995-1999 (SIR: 1.43; 95\% CI: 1.13-1.80) and 1990-2009 (SIR: 1.22; 95\% CI: $1.06-$ $1.41)$; and for all cancers combined among patients operated on during 1995-1999 (SIR: 1.07; 95\% CI: 1.04-1.10), 2000-2004 (SIR: 1.04; 95\% CI: 1.00-1.08), 2005-2009 (SIR: 1.13; 95\% CI: $1.09-$ 1.18 ), and 1990-2009 (SIR: 1.05; 95\% CI: 1.04-1.07). Significantly low SIRs were observed for lung cancer during every calendar period and for cancers of the upper gastrointestinal tract and bladder during the whole study period combined.

Table 3 shows the observed numbers of cancers, SIRs, and 95\% CIs, by time since hip operation. A significant excess of basal cell carcinoma of the skin (SIR: 1.11; 95\% CI: 1.04-1.18), multiple myeloma and other immunoproliferative neoplasms (SIR: 1.37; 95\% CI: 1.09-1.70), and all cancers combined (SIR: 1.10; 95\% CI: 1.07-1.13) occurred during the interval 1-4 years following primary hip surgery. Significantly low SIRs were observed for lung cancer during every follow-up interval, for cancers of the oesophagus during the interval 5-9 years after surgery, and for bladder cancer within a year of surgery or 10 years or more after surgery.

In the subgroup analysis of 1317 patients recorded as undergoing primary resurfacing arthroplasty between 2000 and 2009, during 5698 PYAR, 39 cancers were observed (SIR: 1.23; 95\% CI: $0.87-1.68$ ). These included 10 prostate cancers (SIR: 1.89; 95\% CI: 0.90-3.50), six basal cell carcinomas of the skin (SIR: 0.62; 95\% CI: 0.22-1.36), one cutaneous melanoma (SIR: 0.62; 95\% CI: 0.00-3.56), and no myelomas. Between zero and two cases were observed for remaining cancer sites/types, and no SIRs were significantly different from 1.00 in this subgroup of patients.

\section{DISCUSSION}

Although our results imply an overall excess risk of cancer of 5\% (SIR: 1.05) associated with prior hip arthroplasty, this seems unlikely to be of aetiological or clinical significance. Standardised incidence ratios of a similar order of magnitude (although not quite statistically significant) have been reported previously from a Swedish study (SIR: 1.03; 95\% CI: 1.00-1.06) and for a non-metalon-metal hip replacement cohort from Finland (SIR: 1.04; 95\% CI: 0.99-1.09) (Nyrén et al, 1995; Mäkelä et al, 2012). However, the majority of studies have reported lower than expected risks of cancer overall following hip replacement surgery (Olsen et al, 1999; Paavolainen et al, 1999; Visuri et al, 2003, 2010; Onega et al, 2006; Smith et al, 2012). It has been speculated that this may reflect a 'healthy patient effect' since patients have to have a certain level of 


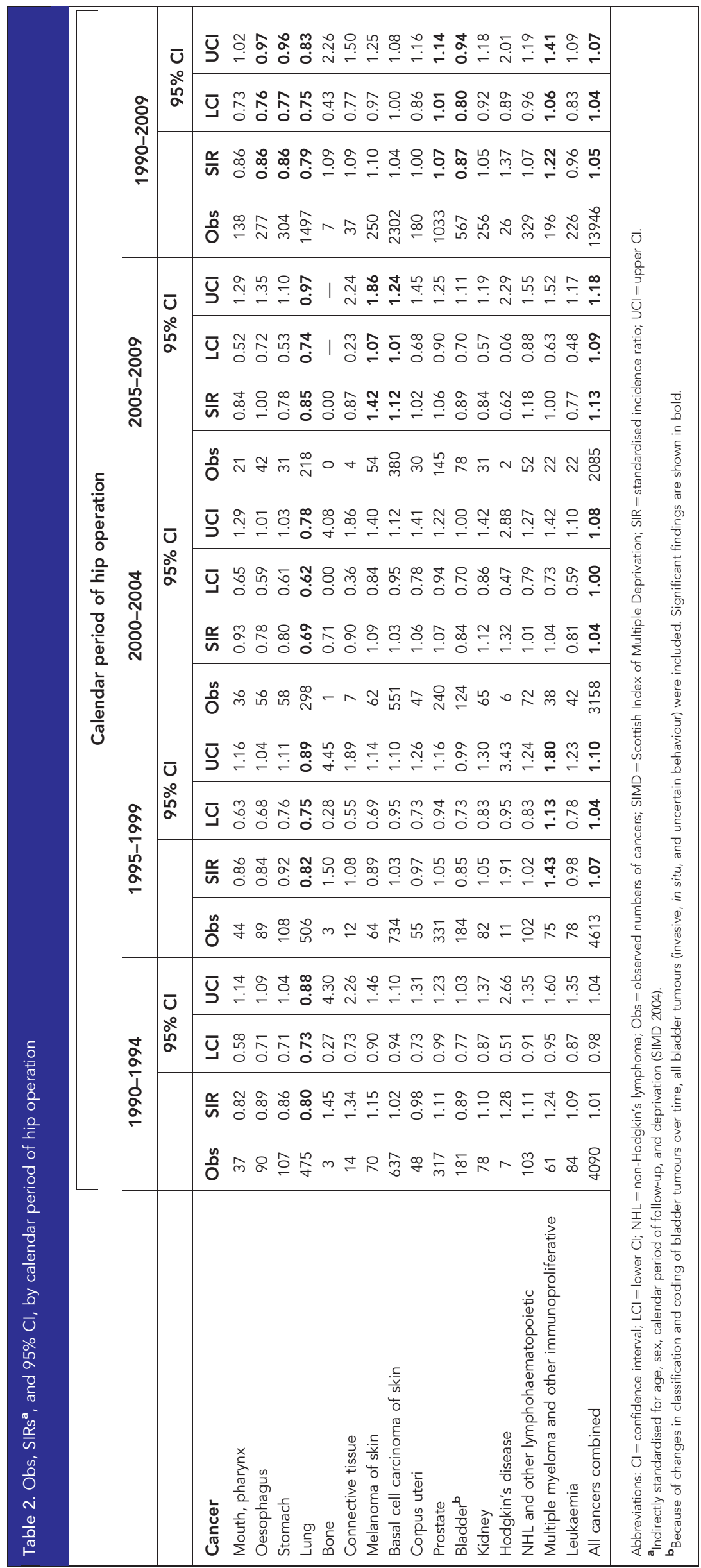




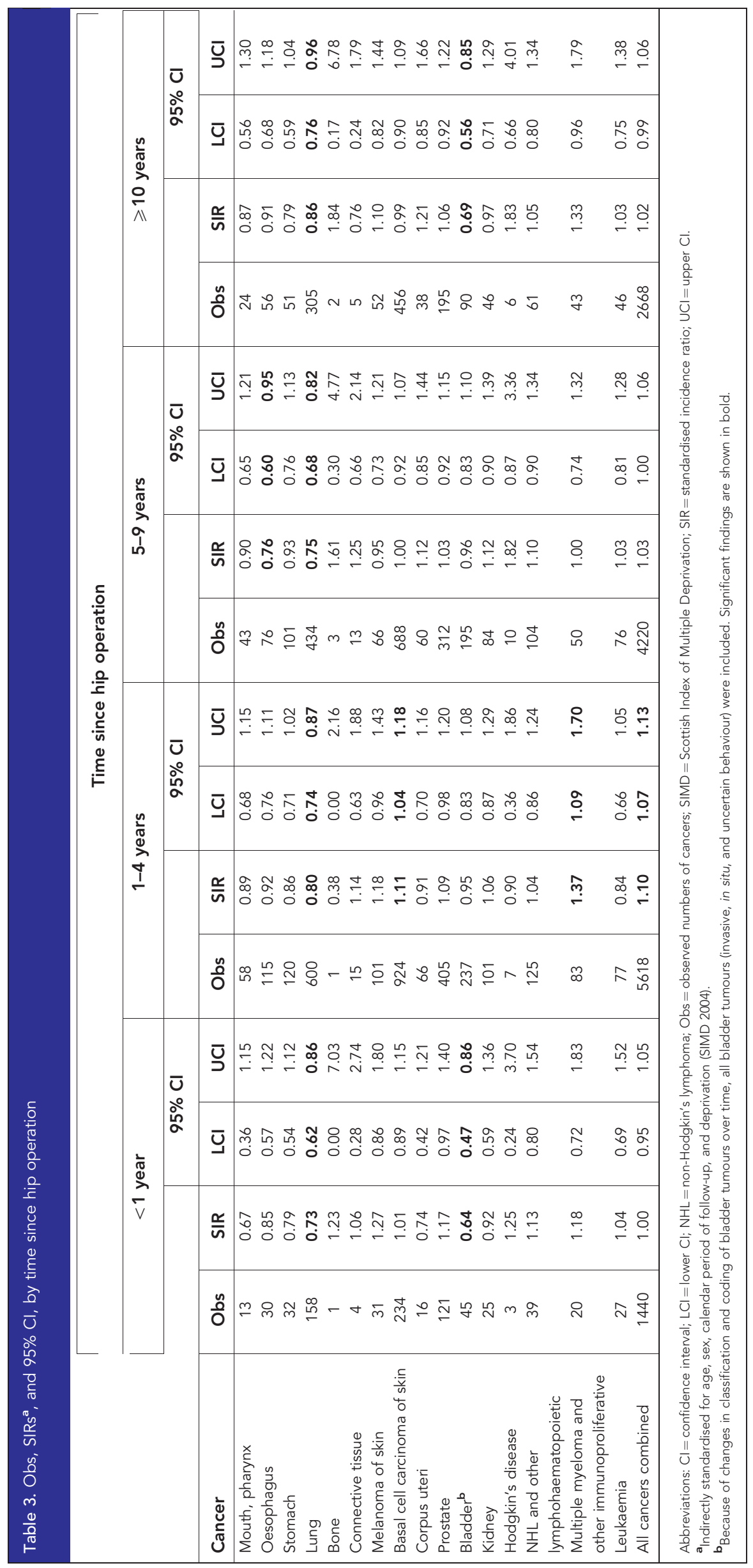


fitness to tolerate major surgery (Paavolainen et al, 1999; Mäkelä et al, 2012; Smith et al, 2012). It might equally reflect higher than average lifetime levels of physical activity (and therefore injury) among some patients presenting with osteoarthritis of the hip, which would tend to reduce the risk of certain cancers (World Cancer Research Fund/American Institute for Cancer Research, 2007). Alternatively, it could reflect the use of medication, such as non-steroidal anti-inflammatory agents, which may also reduce the risk of some cancers (Olsen et al, 1999; Paavolainen et al, 1999).

It is important to note that our study population was not evenly distributed across the deprivation fifths, with a much lower proportion than expected in the most deprived fifth (Table 1). Although our efforts to standardise our results for socioeconomic position may have succeeded in attenuating any 'healthy patient effect', it must be acknowledged that our use of the SIMD 2004 indicator (Scottish Government, 2004), based on the area of residence and imperfect population estimates (see Materials and Methods), is very unlikely to have eliminated all confounding related to this factor. As noted above, it is probable that recipients of hip replacements also differ systematically from the general population in other respects, such as lifestyle factors and medication history, which may determine their risk of developing cancer. We have not been able to make any adjustment for these factors, which may represent additional sources of confounding.

Some previous studies have excluded patients with rheumatoid arthritis at baseline on the grounds that they have a non-typical pattern of cancer (Visuri et al, 1996, 2010; Olsen et al, 1999; Paavolainen et al, 1999; Mäkelä et al, 2012). We did not feel that this was appropriate in our study because a previous study of hospitalised patients with rheumatic diseases in Scotland suggested even more atypical patterns of cancer risk among patients with osteoarthritis: SIRs for all cancers (excluding non-melanoma skin cancer) in patients with rheumatoid arthritis were 1.11 (95\% CI: $1.03-1.21)$ in male patients and 0.96 (95\% CI: 0.90-1.01) in female patients; and in patients with osteoarthritis 0.85 (95\% CI: $0.81-$ 0.88 ) in male patients and 0.83 (95\% CI: $0.80-0.86)$ in female patients (Thomas et al, 2000). The proportion of patients with rheumatoid arthritis (when this has been reported) in previous cohorts of hip replacement patients has typically been low. For example, in a previous study including Scottish patients, only $12 \%$ of the THA cohort had a main diagnosis of rheumatoid arthritis, and adjustment for this in a statistical model did not change the relative risk of leukaemia/lymphoma significantly (Gillespie et al, 1996).

Theoretically, using hospital discharge records, it would also be possible to allow for co-morbid conditions recorded during hospitalisation that have been associated with altered risks of cancer, such as diabetes mellitus (Giovannucci et al, 2010). However, we did not attempt this because, in Scotland at least, there is some evidence of under-recording of comorbid conditions in hospital discharge data (Anwar et al, 2011).

The consistent finding of a lower risk of lung cancer in our cohort has been reported in previous studies (Mathiesen et al, 1995; Visuri et al, 1996, 2003, 2010; Paavolainen et al, 1999; Goldacre et al, 2005; Onega et al, 2006; Mäkelä et al, 2012) and may reflect a lower prevalence of smoking among patients regarded as fit for surgery, or that patients with a history of smoking have been advised to give up before surgery. At the same time, however, there is some evidence that the risk of severe osteoarthritis of the hip may be lower in smokers, at least as far as men are concerned (Visuri et al, 2010). These potential explanations might also account for the deficits we observed in other smoking-related cancers (upper gastrointestinal tract and bladder).

Some other studies have reported excess risks of melanoma of the skin (Nyrén et al, 1995; Olsen et al, 1999; Signorello et al, 2001; Visuri et al, 2003, 2006; Onega et al, 2006; Mäkelä et al, 2012), basal cell carcinoma of the skin (specifically in patients with modern generation metal-on-metal hip replacements) (Mäkelä et al, 2012), and prostate cancer (Nyrén et al, 1995; Signorello et al, 2001). Although the recent UK study (Smith et al, 2012) had the major advantage of being able to focus on metal-on-metal hip replacements by using the National Joint Registry of England to ascertain exposure, their assessment of outcome was based on linkage to hospital episode statistics, which are subject to less quality assurance than cancer registry data, and are likely to be missing information on some cancers, such as cutaneous melanoma, that do not necessarily lead to hospital admission. It has been speculated that the excess risk of melanoma reported in several studies could be due to surveillance bias (Olsen et al, 1999), although we did not observe a significantly increased risk during earlier follow-up intervals. All major types of skin cancer (Doherty et $a l, 2010$ ) and prostate cancer (Shafique et al, 2012) are considerably more common among more affluent individuals, so the increased risks of these cancers observed in our study could reflect residual confounding by socioeconomic position. However, in contrast to the recent Finnish study of patients with modern generation metal-on-metal hip replacements (Mäkelä et al, 2012), our subgroup analysis of patients undergoing primary resurfacing arthroplasty (although based on relatively small numbers) did not show an increased risk of basal cell carcinoma of the skin.

An increased risk of multiple myeloma has been reported in one previous study (Signorello et al, 2001), but this only emerged during long-term follow-up ( $\geqslant 15$ years), which is not really consistent with our findings, and was of borderline statistical significance (SIR 1.86; 95\% CI: 1.01-3.11). Like skin cancer, myeloma may also be susceptible to surveillance bias, related to routine blood testing and X-rays in patients with rheumatic conditions, especially those undergoing surgery. Modestly elevated risks of myeloma have been reported in some (but not all) studies of patients with rheumatoid arthritis as well as some other autoimmune diseases and chronic inflammatory conditions, and some studies have found positive but nonsignificant associations between use of anti-inflammatory medications and myeloma (De Roos et al, 2006). However, none of these associations are entirely consistent or convincing. The majority of studies (Nyrén et al, 1995; Visuri et al, 1996, 2003, 2006, 2010; Olsen et al, 1999; Paavolainen et al, 1999; Goldacre et al, 2005; Onega et al, 2006; Mäkelä et al, 2012) have not shown an increased risk of this malignancy following hip replacement surgery.

Our study has a number of strengths. Hospitalisation data are supported by an active programme of quality assurance including regular assessments of data quality. In relation to discharges from acute hospitals, the accuracy of coding of main operation/ procedure has been estimated to be around $94 \%$ overall and has been relatively stable for around 20 years (Information Services Division, 2012). In particular, the coding of arthroplasty procedures is quality assured in the context of the Scottish Arthroplasty Project (2012), which was established in 1999. Scottish Cancer Registry data have also been shown to be of comparatively high quality (Brewster et al, 1997, 2002), and record linkage in Scotland is believed to be highly accurate and complete (Kendrick and Clarke, 1993).

The main weakness of our study is that, in the absence of a joint register in Scotland, we were unable to assess the risk of cancer separately for all metal-on-metal arthroplasties. Thus, we have only been able to infer the predominant types of prostheses in use based on the era of surgery and local specialist knowledge. Over 4000 patients in receipt of modern generation metal-on-metal prostheses have been identified in a survey of NHS Boards in Scotland (Scottish Government, 2012). However, this represents a relatively small proportion of all patients undergoing hip arthroplasty, and suggests that Scottish orthopaedic surgeons may not have adopted these new generation prostheses with the same enthusiasm as some of their peers in other countries. 
Patients who had their hip surgery in the private sector, not funded by the NHS, are unlikely to be included in acute NHS hospital discharge data, although in Scotland, it is estimated that the majority (well over 90\%) of these procedures are carried out in, or at least funded by, the NHS. Although the linked database in Scotland extends back to 1981, procedure coding is less precise and may have been less accurate in the 1980s. For this reason, we restricted our study to patients operated on from 1990 onwards, meaning that long-term follow-up is somewhat limited, especially for the cohort operated on most recently who are more likely to have received metal-on-metal prostheses. Although we were concerned that we might have overestimated risks by including cases diagnosed in the first year of follow-up, there is little evidence of surveillance bias in our results. Partitioning our analyses by cancer type, period of surgery, and interval of follow-up has inevitably resulted in multiple testing, which increases the risk of a type I error (rejection of a true null hypothesis). At the same time, however, we had limited statistical power to detect altered risks of cancer in our subgroup analysis of patients who had undergone primary resurfacing arthroplasty.

In conclusion, although we observed an increased risk of all cancers combined in our cohort, this was small in magnitude and could easily be the result of confounding. We found no statistically significant evidence of an increased risk of cancer after long-term $(\geqslant 10$ years) follow-up, no evidence of increased risks in our subgroup analysis of patients who underwent primary resurfacing arthroplasty, and for specific types of cancer, no consistent pattern of increased risk across all calendar periods of surgery or intervals of follow-up. The accumulated body of research on this topic does not suggest a major cause for concern. However, follow-up of individuals operated on most recently, who are more likely to have been exposed to new-generation metal-on-metal prostheses, is necessarily limited and it will be important to re-assess the risk of cancer among this group after a further period of follow-up has accrued. Discussions are currently taking place about the feasibility of developing a joint replacement register in Scotland, which in future would provide the possibility of examining cancer risk by type of prosthesis, thereby addressing one of the main limitations of this study.

\section{ACKNOWLEDGEMENTS}

We are grateful to Lee Barnsdale, Doug Clark, and Richard Dobbie for advice and assistance with data preparation before analysis, and to the three anonymous referees for their helpful comments and suggestions.

\section{CONFLICT OF INTEREST}

The authors declare no conflict of interest.

\section{REFERENCES}

Anwar H, Fischbacher CM, Leese GP, Lindsay RS, McKnight JA, Wild SH. Scottish Diabetes Research Network Epidemiology Group (2011) Assessment of the under-reporting of diabetes in hospital admission data: a study from the Scottish Diabetes Research Network Epidemiology Group. Diabet Med 28: 1514-1519.

Brewster D, Crichton J, Harvey JC, Dawson G (1997) Completeness of case ascertainment in a Scottish Regional Cancer Registry for the year 1992. Public Health 111: 339-343.

Brewster DH, Stockton D, Harvey J, Mackay M (2002) Reliability of cancer registration data in Scotland, 1997. Eur J Cancer 38: 414-417.

Cohen D (2011) Out of joint: the story of the ASR. BMJ 342: d2905.
De Roos AJ, Baris D, Weiss NS, Herrington LJ (2006) Multiple myeloma. In Cancer Epidemiology and Prevention, Schottenfeld D, Fraumeni Jr JF (eds)3rd ednpp 919-945. Oxford University Press: New York, NY, USA.

Doherty VR, Brewster DH, Jensen S, Gorman D (2010) Trends in skin cancer incidence by socioeconomic position in Scotland, 1978-2004. Br J Cancer 102: $1661-1664$.

Gillespie WJ, Frampton CM, Henderson RJ, Ryan PM (1988) The incidence of cancer following total hip replacement. [published erratum appears in J Bone Joint Surg (Br) 1996; 78(4): 680] J Bone Joint Surg (Br) 70: 539-542. Gillespie WJ, Henry DA, O'Connell DL, Kendrick S, Juszczak E, McInneny K, Derby L (1996) Development of hematopoietic cancers after implantation of total joint replacement. Clin Orthop Relat Res 329(Suppl): S290-S296.

Giovannucci E, Harlan DM, Archer MC, Bergenstal RM, Gapstur SM, Habel LA, Pollak M, Regensteiner JG, Yee D (2010) Diabetes and cancer: a consensus report. CA Cancer J Clin 60: 207-221.

Goldacre MJ, Wotton CJ, Seagroatt V, Yeates D (2005) Cancer following hip and knee arthroplasty: record linkage study. Br J Cancer 92: 1298-1301.

IARC Monographs on the Evaluation of Carcinogenic Risks to Humans (1999) Surgicalimplants and Other Foreign Bodies. Vol. 74ppInternational Agency for Research on Cancer: Lyon 1-409.

Information Services Division (2012) Assessment of SMR01 Data 2010-2011. Scotland Report May 2012. Available at http://www.isdscotland.org/HealthTopics/Hospital-Care/Publications/2012-05-08/Assessment-of-SMR01Data2010-2011-ScotlandReport.pdf (accessed on 1 February 2013).

Kendrick S, Clarke J (1993) The Scottish Record Linkage System. Health Bull (Edinb) 51: 72-79.

Knight SR, Aujla R, Biswas SP (2011) Total hip arthroplasty - over 100 years of operative history. Orthop Rev 3: e16.

Mäkelä KT, Visuri T, Pulkkinen P, Eskelinen A, Remes V, Virolainen P, Junnila M, Pukkala E (2012) Risk of cancer with metal-on-metal hip replacements: population based study. BMJ 345: e4646.

Mathiesen EB, Ahlbom A, Bermann G, Lindgren JU (1995) Total hip replacement and cancer. A cohort study. J Bone Joint Surg (Br) 77: $345-350$.

Nyrén O, McLaughlin JK, Gridley G, Ekbom A, Johnell O, Fraumeni Jr JF, Adami HO (1995) Cancer risk after hip replacement with metal implants: a population-based cohort study in Sweden. J Natl Cancer Inst 87: 28-33.

Office of Population Censuses and Surveys (1990) Tabular List of the Classification of Surgical Operations and Procedures. Fourth Revision. The Stationery Office: London, UK.

Olsen JH, McLaughlin JK, Nyrén O, Mellemkjaer L, Lipworth L, Blot WJ, Fraumeni Jr JF (1999) Hip and knee implantations among patients with osteoarthritis and risk of cancer: a record-linkage study from Denmark. Int J Cancer 81: 719-722.

Onega T, Baron J, MacKenzie T (2006) Cancer after total joint arthroplasty: a meta-analysis. Cancer Epidemiol Biomarkers Prev 15: 1532-1537.

Paavolainen P, Pukkala E, Pulkkinen P, Visuri T (1999) Cancer incidence in Finnish hip replacement patients from 1980 to 1995: a nationwide cohort study involving 31,651 patients. [published erratum appears in J Arthroplasty 2000; 15:136-137] J Arthroplasty 14: 272-280.

Polyzois I, Nikolopoulos D, Michos I, Patsouris E, Theocharis S (2012) Local and systemic toxicity of nanoscale debris particles in total hip arthroplasty. J Appl Toxicol 32: 255-269.

Scottish Arthroplasty Project (2012) Available at http:// www.arthro.scot.nhs.uk/index. html (accessed on 1 February 2013).

Scottish Government (2004) Scottish Index of Multiple Deprivation 2004. Available at http://www.scotland.gov.uk/Publications/2005/01/20458/ 49127 (accessed on 1 February 2013).

Scottish Government (2012) CEL 23 (2012); available at http://www.sehd. scot.nhs.uk/mels/CEL2012_23.pdf (accessed on 1 February 2013).

Shafique K, Oliphant R, Morrison DS (2012) The impact of socio-economic circumstances on overall and grade-specific prostate cancer incidence: a population-based study. Br J Cancer 107: 575-582.

Signorello LB, Ye W, Fryzek JP, Lipworth L, Fraumeni Jr JF, Blot WJ, McLaughlin JK, Nyrén O (2001) Nationwide study of cancer risk among hip replacement patients in Sweden. J Natl Cancer Inst 93: 1405-1410.

Smith AJ, Dieppe P, Porter M, Blom AW (2012) Risk of cancer in first seven years after metal-on-metal hip replacement compared with other bearings and general population: linkage study between the National Joint Registry of England and Wales and hospital episode statistics. BMJ 344: e2383.

Thomas E, Brewster DH, Black RJ, Macfarlane GJ (2000) Risk of malignancy among patients with rheumatic conditions. Int J Cancer 88: 497-502. 
Vahey JW, Simonian PT, Conrad III EU (1995) Carcinogenicity and metallic implants. Am J Orthop (Belle Mead, NJ) 24: 319-324.

Visuri T, Koskenvuo M (1991) Cancer risk after Mckee-Farrar total hip replacement. Orthopedics 14: 137-142.

Visuri T, Pukkala E, Paavolainen P, Pulkkinen P, Riska EB (1996) Cancer risk after metal on metal and polyethylene on metal total hip arthroplasty. Clin Orthop Relat Res 329(Suppl): S280-S289.

Visuri T, Pukkala E, Pulkkinen P, Paavolainen P (2003) Decreased cancer risk in patients who have been operated on with total hip and knee arthroplasty for primary osteoarthrosis: a meta-analysis of 6 Nordic cohorts with 73,000 patients. Acta Orthop Scand 74: 351-360.

Visuri TI, Pukkala E, Pulkkinen P, Paavolainen P (2006) Cancer incidence and causes of death among total hip replacement patients: a review based on

\section{APPENDIX 1}

Table 1. Cancers investigated in the study, and their diagnostic codes according to the ninth (ICD-9) and tenth (ICD-10) revisions of the International Classification of Diseases

\begin{tabular}{|l|c|c|}
\hline Cancer & ICD-9 & ICD-10 \\
\hline Mouth, pharynx & $141,143-149$ & $\begin{array}{c}\text { C01-C06, } \\
\text { C09-C14 }\end{array}$ \\
\hline Oesophagus & 150 & C15 \\
\hline Stomach & 151 & C16 \\
\hline Lung & 162 & C33, C34 \\
\hline Bone & 170 & C40, C41 \\
\hline Connective tissue & 171 & C47, C49 \\
\hline Melanoma of skin & 172 & C43 \\
\hline Basal cell carcinoma of skin & 173, ICD-O & C44, ICD-O \\
& M-809 & M-809 \\
\hline
\end{tabular}

Nordic cohorts with a special emphasis on metal-on-metal bearings. Proc Inst Mech Eng H 220: 399-407.

Visuri T, Pulkkinen P, Paavolainen P, Pukkala E (2010) Cancer risk is not increased after conventional hip arthroplasty. Acta Orthop 81: 77-81.

World Cancer Research Fund/American Institute for Cancer Research (2007) Food, Nutrition, Physical Activity, and the Prevention of Cancer: a Global Perspective. AICR: Washington, DC, USA, pp 198-209.

This work is published under the standard license to publish agreement. After 12 months the work will become freely available and the license terms will switch to a Creative Commons AttributionNonCommercial-Share Alike 3.0 Unported License.

\section{Table 1. (Continued)}

\begin{tabular}{|l|c|c|}
\hline Corpus uteri & 182 & C54 \\
\hline Prostate & 185 & C61 \\
\hline Bladder* & $188,233.7,236.7$, & C67, D09.0, \\
& 239.4 & D41.4 \\
\hline Kidney & 189 & C64, C65 \\
\hline Hodgkin's disease & 201 & C81 \\
\hline $\begin{array}{l}\text { NHL and other lymphohaemato- } \\
\text { poietic }\end{array}$ & $\begin{array}{c}200,202.0-202.3, \\
202.5-202.8\end{array}$ & C82-C85, C96 \\
\hline $\begin{array}{l}\text { Multiple myeloma and other } \\
\text { immunoproliferative }\end{array}$ & 203 & C88, C90 \\
\hline Leukaemia & $202.4,204-208$ & C91-C95 \\
\hline All cancers combined & $140-208$ & C00-C96 \\
\hline \multicolumn{2}{|l|}{} \\
$\begin{array}{l}\text { *Because of changes in classification and coding of bladder tumours over time, all bladder } \\
\text { tumours (invasive, in situ, and uncertain behaviour) were included. }\end{array}$ \\
\hline
\end{tabular}

